OPEN ACCESS

Edited by:

Luis Del Valle,

Louisiana State University,

United States

Reviewed by:

Valeria Pietropaolo,

Sapienza University of Rome, Italy

Maria Grazia Romanelli,

University of Verona, Italy

*Correspondence:

Mauro Tognon

tgm@unife.it

Fernanda Martin

mr@unife.it

${ }^{\dagger}$ Present address:

Giovanni Guerra,

Clinical Chemistry Laboratory,

City Hospital, Bergamo, Italy

${ }^{\ddagger}$ These authors have contributed equally to this work

Specialty section:

This article was submitted to

Viral Immunology,

a section of the journal

Frontiers in Immunology

Received: 22 November 2020 Accepted: 07 May 2021

Published: 25 May 2021

Citation:

Torreggiani E, Bononi I, Pietrobon S, Mazzoni E, Guerra G, Feo C, Martini F and Tognon M (2021) Colorectal Carcinoma Affected Patients Are

Significantly Poor Responders Against the Oncogenic JC Polyomavirus.

Front. Immunol. 12:632129. doi: 10.3389/fimmu.2021.632129

\section{Colorectal Carcinoma Affected Patients Are Significantly Poor Responders Against the Oncogenic JC Polyomavirus}

\author{
Elena Torreggiani ${ }^{1 \neq}$, Ilaria Bononi ${ }^{2 \neq}$, Silvia Pietrobon ${ }^{1}$, Elisa Mazzoni ${ }^{1}$, Giovanni Guerra ${ }^{3 \dagger}$, \\ Carlo Feo ${ }^{1}$, Fernanda Martini ${ }^{1 *}$ and Mauro Tognon ${ }^{1 *}$ \\ ${ }^{1}$ Department of Medical Sciences, School of Medicine, University of Ferrara, Ferrara, Italy, ${ }^{2}$ Department of Translational Medicine, \\ School of Medicine, University of Ferrara, Ferrara, Italy, ${ }^{3}$ Clinical Laboratory Analysis, University-Hospital of Ferrara, Ferrara, Italy
}

Background: Many investigations reported the association between human tumors and JCPyV, a polyomavirus with oncogenic potential. The association has been supported by studies that found JCPyV footprints in CRC and gliomas of different types. Indeed, JCPyV footprints including its nucleic acids and Tag oncoprotein have been revealed in CRC tissues.

Methods: Herein, sera from colorectal carcinoma (CRC) affected patients and healthy individuals (HS), employed as control, were analysed for immunoglobulin G (lgG) antibodies against specific JCPyV viral capsid protein 1 (VP1) antigens. The investigation was carried out employing an innovative immunological assay. Indeed, an indirect enzyme-linked immunosorbent assay (ELISA) with JCPyV VP1 mimotopes was used. JCPyV VP1 mimotopes consisted of synthetic peptides mimicking VP1 epitopes.

Results: Sera from CRC affected patients, evaluated using indirect ELISAs with synthetic mimotopes, showed a significant lower prevalence of IgG antibodies against JCPyV VP1 mimotopes (26\%) compared to HS (51\%), $\mathrm{p}<0.005$. These data were confirmed by another method, the hemagglutination inhibition (HAl) assay. Altogether these results, i.e. the prevalence of serum IgG antibodies against JCPyV VP1 mimotopes from patients with $\mathrm{CRC}$ is approximately $50 \%$ lower than in $\mathrm{HS}$, are of interest.

Discussion: Our data suggest that patients with CRC are significantly poor responders against JCPyV VP1 antigens. It is possible that CRC patients are affected by a specific immunological deregulation. This immunological dysfunction, revelled in CRC patients, may account for their predisposition to the colorectal carcinoma onset.

Keywords: colorectal carcinoma, polyomavirus, JCPyV, oncogenic, antigen, antibody, prevalence, mimotope 


\section{INTRODUCTION}

Colorectal carcinoma (CRC) is a tumour arising at high frequency in distinct human populations. CRC can be a fatal tumour $(1,2)$, and is responsible of approximately $10 \%$ of all malignancies in humans (3). So far, several risk factors associated with CRC aetiology have been revealed, including infectious agents, biology background and lifestyle (4-7).

Among viruses with oncogenic potential, different polyomaviruses have been investigated for their association with human tumors. JCPyV is a neurotropic and oncogenic polyomavirus, which has a pivot role in the onset of multifocal leukoencephalopathy (PML). In addition, human tumors of different hystotypes tested JCPyV-positive. Indeed, many investigations found $\mathrm{JCPyV}$ associated with cancers of the central nervous system (CNS), such as gliomas of different types and colorectal carcinomas (8-10). However, other studies reported negative data (11).

JCPyV is considered an opportunistic pathogen (12) which infection occurs in the first years of life. JCPyV is present in the adult population with a prevalence ranges from 50 to $60 \%$ (13) and the prevalence reaches $70 \%$ in the elderly (14). JCPyV is constituted by a circular double strand DNA of $5.13 \mathrm{~Kb}$ (15). Its genome is characterized by two main coding regions named early and late regions. The viral oncoproteins large $\mathrm{T}$ (Tag), small $\mathrm{t}$ (tag) antigens, together with the multifunctional agnoprotein (agno) are encoded by the early region sequences, whereas the three viral capsid proteins VP1, VP2 and VP3, which are structural proteins, are encoded by the late region. Moreover, JCPyV genome has a non-coding region (NCCR), with a regulatory function (16).

JCPyV has been investigated for its role in the development of gastrointestinal cancers, including CRC $(17,18)$. Many independent studies reported the detection of JCPyV nucleic acids or proteins, and in particular the oncoprotein Tag, in various human tissues including adenomatous polyp tissues and colorectal adenocarcinomas; they have also been found in normal tissues and adjacent non-cancerous tissues (19).

$\mathrm{JCPyV}$, with its viral oncoprotein Tag, is able to induce chromosomal instability in colonic cells. This mechanism of action favors gross chromosomal rearrangements, loss of heterozygosity and aneuploidy which may facilitate, during the multistep phases of the tumorigenesis, the cell transformation of colorectal cells (20). In addition, other investigations detected JCPyV DNA, Tag and the JCPyV-specific microRNA 5p (miRJ1-5p) in CRC biopsies, being their presence associated with the tumor development $(7,21-23)$. However, other studies did not identify JCPyV DNA sequences in hyperplastic polyps/adenoma and adenocarcinoma and normal tissues (11, 24-26). The reasons for these contrasting data reported by different investigations are not known. However, these contrasting results may be due to different protocols employed during the sample collection and processing, JCPyV testing, different genetic background of patient populations (27).

The association between JCPyV and CRC has been poorly studied (28-31). To date, investigations in this field show inconclusive and conflicting, results about the putative involvement of JCPyV in CRC. Discrepancies of data on the association between JCPyV and CRC could be due to the crossreactivity of the $\mathrm{JCPyV}$ proteins, used as antigens in immunological tests. Indeed, JCPyV antigens share an extensive amino acid homology with BK (BKPyV) and simian virus 40 (SV40), which belong to polyomavirus family, too (13, 32-35). In this context, it should be recalled that CRC, with an incidence and mortality rate expected to increase more than $60 \%$ up to 2030, represents a global emergency (3). Conflicting results, emerging from different studies, suggest that the association between JCPyV and CRC deserves further investigations.

Recently, an innovative immunological test to reveal serum $\mathrm{JCPyV}$-antibodies has been reported. This test is based on the use of two synthetic peptides, named mimotopes used as antigens of JCPyV viral capsid protein 1 (VP1) in an indirect enzyme-linked immunosorbent assay (ELISA) $(13,36)$.

The main goal of this investigation is to verify JCPyV antibodies in sera from CRC affected patients employing two immunological tests, i.e. an innovative indirect ELISA with JCPyV mimotopes and the Haemagglutination Inhibition (HAI) assay. The combination of the two tests was employed to confirm the specificity of the results $(13,37)$.

\section{MATERIALS AND METHODS}

\section{Serum Samples}

Blood samples were obtained from the Clinical Laboratory Analysis, University Hospital of Ferrara. Specifically, samples $(n=53)$ were from patients affected by colorectal carcinoma (CRC) at the time of collection and healthy subjects ( $n=89$; HS). Briefly, whole blood was collected anonymously, coded with indications of age, gender and pathology. After clot formation, blood samples were centrifuged at $800 \mathrm{~g}$ for $10 \mathrm{~min}$., whereas the resulting supernatant serum was carefully removed. Approximately $500 \mu \mathrm{l} \div 1 \mathrm{ml}$ of serum was collected from each blood sample. Sera were then divided into aliquots and stored at $-80^{\circ} \mathrm{C}$ until the time of the analysis.

\section{Ethical Statement}

The County Ethical Committee of the University Hospital of Ferrara approved this study, number 151078. All CRC patients and HS subjects gave written informed consent to the scientific research at the time of the hospital admission, in compliance with the Declaration of Helsinki.

\section{JCPyV VP1 Mimotopes}

As previously described (13), computer-assisted analyses enabled to select two specific peptides from the JCPyV viral capsid protein 1 (VP1) sequences. Given the high homology among viruses belonging to the polyomavirus family, the sequence of selected JCPyV specific peptides was compared with the same region of the highly homologous BKPyV and SV40 polyomaviruses and with the same region of other less homologous viruses (http://blast.ncbi.nlm.nih.gov).

JCPyV specific peptides named VP1 K and VP1 N have the following amino acid sequences: 
1. VP1 K:NH2-KSISISDTFESDSPNRD-COOH(17 a.a, 60-76);

2. VP1 N: NH2-LMNVHSNGQATHDNGAGK-COOH (18 a.a, 118-135).

Previous indirect ELISA results $(13,36)$, indicate that JCPyV VP1 K and VP1 N peptides did not cross-react with the BKPyV and SV40 hyperimmune sera used. An unrelated polyomavirus human peptide, the human neuropeptide S (hNPS), was employed as a negative control antigen. The a.a. sequence of hNPS has been previously reported $(38,39)$. Peptides, synthesized by standard procedures, were purchased from UFPeptides s.r.l. (Ferrara, Italy).

\section{Indirect Enzyme-Linked Immunosorbent Assay}

JCPyV synthetic peptides, named VP1 K and VP1 N were developed as antigens in an indirect ELISA which was standardized to identify specific antibodies against JCPyV in human sera $(13,36,40)$.

\section{Peptide Coating}

Ninety-six-well flat bottom plate (Nunc-Immuno plate PolySorp; Thermo Fisher Scientific, Milan, Italy), was coated with $5 \mu \mathrm{g}$ of the selected peptide for each well diluted in $100 \mu \mathrm{l}$ of Coating Buffer (Candor Bioscience, Weissensberg, Germany). The plate was incubated at $4^{\circ} \mathrm{C}$ for $16 \mathrm{~h}$ allowing the peptide to cover the bottom well completely.

\section{Peptide Blocking}

The plate was rinsed three times with Washing Buffer (Candor Bioscience) using a microplate washer (model Wellwash 4MK2; Thermo Electron Corporation, Vantaa, Finland). This procedure removes uncoated peptides. Blocking was performed with 200 $\mu \mathrm{l} /$ well of the Blocking Solution (Candor Bioscience) at $37^{\circ} \mathrm{C}$ for $90 \mathrm{~min}$.

\section{Serum Sample Addition}

After the blocking step the three washes with Washing Buffer (Candor Bioscience) were repeated. Then, $100 \mu$ l of human serum samples under investigation were added to the plate. Moreover, $100 \mu \mathrm{l}$ of the following sera were added in other wells of the same plate and used as controls: (i) an immune rabbit serum containing anti-JCPyV antibodies represented the positive-control; (ii) human immune sera anti-SV40 antibodies, (iii) human immune sera anti-BKyV antibodies, and (iv) three human serum samples which were found to be JCPyV negative in previous studies (35), represented the negative controls. Each human sample was diluted 1:20 in Low Cross Buffer (Candor Bioscience) and analysed three times. The plate was incubated at $37^{\circ} \mathrm{C}$ for $90 \mathrm{~min}$.

\section{Secondary Antibody Addition}

After incubation, a new triple rinsing cycle was repeated as described above. Then, the secondary antibody solution was added to each well. The solution consists of a goat anti-human or anti-rabbit Ig-G heavy and light chain specific peroxidaseconjugate (Calbiochem-Merck, Darmstadt, Germany) diluted
1:10,000 in Low Cross Buffer (Candor Bioscience) was incubated at room temperature for $90 \mathrm{~min}$.

\section{Dye Treatment and Spectrophotometric Reading}

Following incubation, the plate was rinsed three times with the Washing Buffer (Candor Bioscience) and then treated with 100 $\mu \mathrm{l}$ of 2,2'- azino-bis 3-ethylbenzthiazoline-6-sulfonic acid solution (Sigma-Aldrich, Milan, Italy), which reacts with the peroxidase enzyme, enables the color reaction. After $45 \mathrm{~min}$ at room temperature, $100 \mu \mathrm{l}$ of citric acid $0.1 \mathrm{M}$ was used to block the colorimetric reaction. The spectrophotometer (model Multiskan EX; Thermo Electron Corporation) was employed to read the plate at a wavelength $(\lambda)$ of $405 \mathrm{~nm}$. Color intensity in wells was determined by optical density (OD) reading that corresponds to the amount of immune complexes formed, which in turn depends on the quantity of specific antibody against JCPyV is present in samples tested.

\section{Cut-off Determination}

The cut-off value in each assay was determined using an OD reading of the three negative control sera added three times to the standard deviation $(+3 \mathrm{SD})(13,35,36)$. The three JCPyV negative control sera were chosen from those below the cut-off value calculated using second-degree polynomial regression by plotting the ranked net OD individual values for VP1 K and VP1 $\mathrm{N}$ peptides, as previously published for $\mathrm{MCPyV}$ and $\mathrm{BKPyV}$ virus-like particles (VLPs) $(41,42)$. Sera with JCPyV VP1 antibodies were considered positive upon reacting to both peptides from the late region.

Result reproducibility was determined by performing three independent replicates of the experiment carried out by different operators. The specificity and sensitivity of the results observed with the indirect ELISA, were confirmed by comparing the immunological data with the results obtained by the haemagglutination inhibition (HAI) assay.

\section{JCPyV Haemagglutination (HA) and Haemagglutination-Inhibition (HAl) Assays}

JCPyV titre was assessed by haemagglutination (HA) with a solution of human erythrocytes, group $0, \mathrm{Rh}+$. These erythrocytes agglutinate in the presence of a specific concentration of JCPyV virions, forming a network that keeps red cells in suspension. On the contrary, in the absence or with a low virion concentration, red cells precipitate and form a red spot on the bottom of the well $(37,43)$. Serial dilutions of the viral working stock purchased from the American Type Culture Collection (ATCC, VR-1583), were carried out in 96 well round bottom plates (Thermo Fisher Scientific, Milan, Italy). Specifically, the titration of JCPyV was based on serial 1:2 dilutions of the virus in Dulbecco's Phosphate Buffered Saline, DPBS 1X (Lonza, Milan, Italy) from 1:10 to 1:5120, in $100 \mu \mathrm{L}$ of final volume. Then, $50 \mu \mathrm{L}$ of $1 \%$ erythrocytes, were added to each viral dilution. Plates were incubated at $4^{\circ} \mathrm{C}$, whereas the HA titre was read $4 \mathrm{~h}$ later when the control, represented by erythrocytes in DPBS only, had completely sedimented on the well bottom. The HA titre was determined based on the highest viral dilution that causes a complete haemagglutination $(13,37)$. The viral titre established by $\mathrm{HA}$ assay was $3.2 \times 10^{3}$ haemagglutinating 
units (HU), corresponding to $3.2 \times 10^{7}$ plaque-forming unit in $1 \mathrm{ml}$ (PFU/ml).

Haemagglutination-inhibition (HAI) assay tests the capacity of JCPyV immune serum samples from CRC and HS to inhibit the haemagglutination ability of the virus. Serial dilutions (1:16, $1: 32,1: 64,1: 128)$ of serum were employed to calculate the antibody titre. Sera were heated at $56^{\circ} \mathrm{C}$ for $30 \mathrm{~min}$ and treated with $0.1 \mathrm{M}$ sodium periodate $\left(\mathrm{NaIO}_{4}\right)$ to remove non-specific inhibitors. Specifically, $30 \mu \mathrm{L}$ of serum diluted 1:2 was added to $15 \mu \mathrm{L}$ of $\mathrm{NaIO}_{4}$, in 96 well round bottom plates (Thermo Fisher Scientific, Milan, Italy) and incubated at room temperature for $30 \mathrm{~min}$. Then, $15 \mu \mathrm{L}$ of $5 \%$ glycerine was added to each serum. Serum serial dilutions in DPBS $1 \mathrm{x}$, from $1: 16$ to $1: 128$, were mixed with 8 haemagglutinating units (H.U.) of JCPyV as antigen. Mixtures were maintained at room temperature for $1 \mathrm{~h}$. Then, $1 \%$ of human erythrocytes solution, group $0, \mathrm{Rh}+$, was added, then plates were incubated at $4^{\circ} \mathrm{C}$ for $4 \mathrm{~h}$. As previously described $(37,44)$, the HAI titre was calculated based on the highest dilution of each immune serum sample that completely abolish the viral HA.

\section{Statistical Analysis}

The differences between the prevalence of anti-JCPyV antibodies in the sera of the different groups of subjects studied (CRC and HS) were analyzed statistically. $\chi 2$ test with Yates' correction was employed to compare binary variables. Fisher's exact test was used to compare the prevalence of anti-JCPyV antibodies between CRC patients and HS subjects. The serologic profile (OD) of serum antibody reactivity to JCPyV mimotopes was statistically analyzed using a one-way t-student test.

The comparability of age and gender distribution between CRC and HS was evaluated by student's t-test. $\mathrm{P}<0.05$ values were considered statistically significant. All statistical analyses were carried out using GraphPad Prism 6 software (GraphPad software, La Jolla, CA, USA).

\section{RESULTS}

\section{Identification of JCPyV Antibodies in Patients Affected by Colorectal Carcinoma Through an Indirect E.L.I.S.A.}

Sera were from colorectal carcinoma affected patients (CRC, $\mathrm{n}=$ 53) healthy subjects (HS, $n=89$ ), employed as the control group. The two cohorts had similar median age distribution and gender (Table 1), were evaluated for IgG antibodies (abs) reacting to JCPyV VP1 mimotopes, known as VP1 K and VP1 N. To this aim, an indirect ELISA was developed using the aforementioned synthetic peptides as viral antigens $(13,36)$, whereas a human peptide, hNPS, which is not associated to polyomavirus proteins, was the control $(38,44)$. CRC and HS serum samples were diluted 1:20, then evaluated for their reactivity to JCPyV VP1 epitopes in indirect ELISAs.

Sera reacting to JCPyV VP1 K mimotope achieved a prevalence of $26 \%(14 / 53)$ in CRC, while the prevalence observed in the control group was $61 \%(54 / 89)$.

The same test was then exploited to investigate the IgG class of abs against the other JCPyV VP1 mimotope, the peptide N. It resulted that $\mathrm{JCPyV}$ VP1 mimotope $\mathrm{N}$ was revealed in serum samples with a prevalence of $30 \%(16 / 53)$ in CRC, whereas in HS the prevalence was $70 \%(62 / 89)$.

Interestingly, the two prevalence of IgG antibodies against JCPyV peptide $\mathrm{N}$ and peptide $\mathrm{K}$ did not statistically differ in the analyzed samples (Table $\mathbf{1}$ ).

In this investigation, JCPyV VP1-positive sera were those samples that reacted to both polypeptides $\mathrm{K}$ and N. Putting together the results of positive sera for both JCPyV VP1 K and VP1 N mimotopes, a prevalence of 26\% (14/53) in CRC and 51\% (45/89) in HS was achieved, being the different prevalence between the two groups statistically significant $(\mathrm{p}<0.001)$ (Table 1$)$.

JCPyV-positive sera assessed by indirect ELISA presented a general cut-off, between 0.17-0.19 OD (spectrophotometric reading). This cut-off level discriminated JCPyV-negative (sera below OD 0.17-0.19) from JCPyV-positive sera (above OD 0.170.19). The JCPyV hyperimmune serum, used as positive control, reached an OD of up to 1.8, whereas BKPyV and SV40 hyperimmune serum samples, the negative controls, showed an OD $<0.01$. The human peptide hNPS, used as a negative control, revealed an OD below 0.1. The 2 indirect ELISAs, with 2 distinct JCPyV VP1 K and N peptides showed similar data, thus corroborating the detection of abs against JCPyV VP1 in CRC serum samples, even if at a significant lower prevalence compared to HS (Table 1).

CRC and HS serum antibody reactivity to JCPyV peptides is displayed in Figure 1. Scatter dot plot shows the dispersion of $\mathrm{OD}$ values to a mean level represented by the line inside the scatter for CRC and HS cohorts.

As shown in Figure 1A, the mean OD for VP1 K was $0.187 \pm$ 0.022 in CRC sera and $0.369 \pm 0.026$ in HS. Similarly, the mean OD for VP1 N was $0.177 \pm 0.011$ in CRC samples and $0.345 \pm$ 0.022 in controls (Figure 1B). The combination of both VP1 K and VP1 N data, results in a mean OD of $0.182 \pm 0.012$ in CRC sera and $0.357 \pm 0.017$ in HS subjects (Figure 1C), with a statistically significant difference between the two groups in all immunological data set analyzed ( $<<0001$; Figure 1).

TABLE 1 | Prevalence of serum immunoglobulin G antibodies reacting to JCPyV viral capsid protein 1 (VP1) mimotopes in indirect ELISA.

\begin{tabular}{|c|c|c|c|c|c|c|}
\hline \multirow[t]{2}{*}{ Human serum } & \multirow[t]{2}{*}{ N. of samples } & \multirow[t]{2}{*}{ Median age \pm SD } & \multirow[t]{2}{*}{ Male (\%) } & \multicolumn{3}{|c|}{ N. of positive samples (\%) } \\
\hline & & & & VP1 $\mathrm{K}$ & VP1 N & VP1 $(K+N)$ \\
\hline $\mathrm{CRC}$ & 53 & $69 \pm 12$ & $33(62)$ & $15(28)$ & $16(30)$ & $14(26)^{\star \star}$ \\
\hline HS & 89 & $61 \pm 11$ & $58(65)$ & $54(61)$ & $62(70)$ & $45(51)$ \\
\hline
\end{tabular}

Human sera were from patients affected by colorectal carcinoma (CRC) and healthy subjects (HS). The prevalence of JCPyV antibodies in CRC patients is statistically lower than that detected in HS $\left(^{* *} p=0.0047\right)$. 


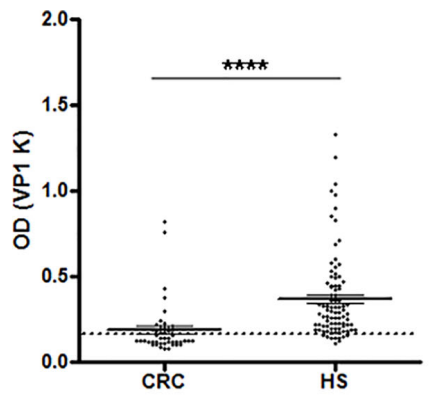

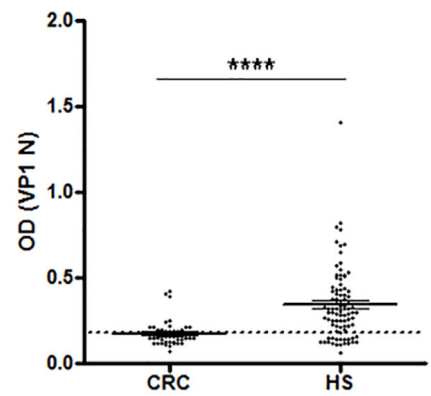

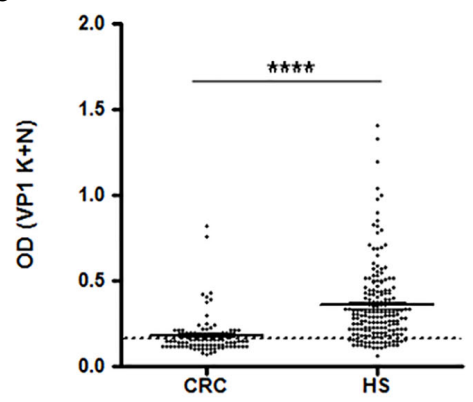

FIGURE 1 | Serologic profile of human serum antibody reactivity to JCPyV viral capsid protein 1 (VP1) mimotopes. Immunologic data are from patients affected by colorectal carcinoma (CRC) and healthy subjects (HS). Results are shown as values of optical density (OD) readings at $\lambda 405 \mathrm{~nm}$ for serum samples diluted $1: 20$ and analyzed by indirect ELISA. Each scatter plot represents the dispersion of individual OD values to a mean level, defined by the line inside the scatter with standard error of the mean (SEM) for each group patients/subjects evaluated. The mean OD for VP1 K (A), VP1 N (B) and VP1 (K+N) (C) in CRC sera are statistically lower than that observed in HS $\left.{ }^{\star \star \star \star} \mathrm{p}<0.0001\right)$. Dotted line indicates the cut-off value.

\section{Prevalence of Serum Anti-JCPyV Antibody Obtained by the Haemagglutination Inhibition (HAl) Assay}

We reported in previous investigations, that the indirect ELISA with JCPyV VP1 peptides specificity is confirmed by the Hemagglutination Inhibition (HAI) assay $(13,37)$. Indeed, HAI test detects serum specific anti-JCPyV antibodies, which are able to abolish the viral agglutination property and evaluates their titre in the sample. To this purpose, serum samples $(n=89)$ from HS and CRC $(n=53)$ affected patients were serially diluted from $1: 16 ; 1: 32 ; 1: 64$; to $1: 128$ and evaluated by HAI test.

Seroprevalence of JCPyV-positive samples, diluted 1:128, was $28 \%(15 / 53)$ in the CRC cohort, whereas in the HS group the prevalence was $51 \%(45 / 89)$. The difference of JCPyV seroprevalence between CRC and HS cohorts was statistically significant $(\mathrm{p}<0.05)$ (Table 2). The dilution 1:128 was selected since lower dilutions include antibodies at higher level, which could give false positive results (37). Interestingly, the prevalence of JCPyV-positive samples resulted from HAI assay and indirect ELISA did not differ statistically $(\mathrm{p}>0.05)$.

\section{DISCUSSION}

At present, the colorectal carcinoma (CRC) is a frequent tumor, responsible of a high mortality in distinct populations. Because of its negative impact CRC is considered a significant health concern (3). The percentage of CRC incidence is currently increasing in many geographic areas, thereby representing a worldwide health problem (45). CRC arises through a multistep process characterized by several events, such as different genetic and epigenetic modifications in the human DNA, and the involvement of exogenous factors, such as lifestyle, diet, environment and viral infections $(6,7,46)$. Indeed, viral agents such herpes simplex virus (HSV), human papillomavirus (HPV), Epstein-Barr virus (EBV), Cytomegalovirus (CMV) and JC polyomavirus (JCPyV) have been associated to the CRC onset. It should be recalled that these viruses are considered potential risk factors for the onset of different gastrointestinal tract tumors, such as oesophagus, stomach and colorectal cancers (47-50).

In order to investigate the putative association between JCPyV and CRC, several studies assessed JCPyV presence and/ or its genes expression or seroreactivity in CRC. Overall, these reports detected JCPyV footprints in CRCs and normal mucosal tissues. Other studies reported negative data. It is possible that discordant findings could be due, at least in part, to the analysis of different markers and distinct approaches employed $(7,31)$.

In this investigation, sera from CRC patients and healthy subjects (HS), the control, were evaluated for their reactivity to JCPyV VP1 mimotopes using a specific indirect ELISA and HIA approach. Our immunological data indicate that specific IgG abs against JCPyV antibodies are present in both human sera from CRC patients and HS. Specifically, the overall prevalence of IgG

TABLE 2 | Prevalence of serum immunoglobulin G antibodies against JCPyV assessed by haemagglutination inhibition (HAl) assay.

\begin{tabular}{|c|c|c|c|c|c|c|c|}
\hline Human serum & N. of samples & Median age \pm SD & Male (\%) & \multicolumn{4}{|c|}{ N. of positive samples (\%) } \\
\hline HS & 89 & $61 \pm 11$ & $58(65)$ & $79(89)$ & $78(88)$ & $69(77)$ & $45(51)$ \\
\hline
\end{tabular}

Human sera from patients affected by colorectal carcinoma (CRC) and healthy subjects (HS) were evaluated by HAl assay. The prevalence of JCPyV antibodies in CRC sera, diluted 1:128, is statistically lower than that detected in HS $\left({ }^{* *} p=0.0094\right)$. 
antibodies against JCPyV VP1was 26\% in CRC and 51\% in HS. This result reveals that the prevalence of abs against JCPyV in sera from colorectal carcinoma patients is significantly lower than HS ( $p<0.001$ ). It should be noted that the prevalence of JCPyV-positive samples revealed by the indirect ELISA with mimotopes did not differ from that determined by HAI test. Indeed, the prevalence of JCPyV-positive sera from CRC patients and $\mathrm{HS}$ was $28 \%$ and $51 \%$, respectively.

Our findings are in agreement with two earlier serological studies, where the association between JCPyV and colorectal carcinoma was investigated using ELISAs with virus-like particles (VLPs). In these prospective studies, JCPyV seroprevalence was lower in CRC cases than in controls $(28,29)$. However, it is worth mentioning that investigations reporting immunological results with virus-like particles or recombinant VP1 could be due to non-specific methods employed. Indeed, the high homology of VP1 amino acid sequences among JCPyV, BKPyV and SV40 polyomaviruses, may give rise to some cross-reactivity results $(13,34,35,51-54)$.

Herein, JCPyV seroreactivity was tested employing 2 distinct techniques: (i) an innovative indirect ELISA with 2 different mimotopes of the JCPyV VP1, which detected JCPyV specific IgG antibodies in CRC and HS serum samples. This innovative immunological method did not show cross-reactivity with homologue polyomaviruses, such as BKPyV and SV40; (ii) the HAI method to corroborate the JCPyV specificity and to verify the results obtained by the indirect ELISA.

Interestingly, the lower seroprevalence of IgG antibodies from CRC patients reacting to JCPyV VP1 antigens obtained in the present investigation, has also been detected in non-Hodgkin's lymphomas (55) as well as in a cohort of patients affected by multiple sclerosis as described in our recent investigation (36).

Our immunological data suggest that CRC patients are significantly poorly responders to JCPyV VP1 antigens. It is possible that the reduced ability of CRC patients to react to JCPyV VP1 antigens could be due to their oncologic status. In addition, different exogenous factors which may contribute to the CRC onset, could also affect normal replicating cells belonging to the immune system. Numerous immune alterations were observed in CRC of different grade. Significant dysfunctions of the anticancer immunity of the host have been described in the CRC onset mostly depending on escape mechanisms implemented by transformed cells to establish a suitable growth environment (5658). Tumor microenvironment, where inflammatory and immune cells acting key roles in either controlling tumor growth or promoting a chronic inflammation status, may favour the CRC progression through the induction of immune suppressive mechanisms $(59,60)$. For example, in advanced CRC, malignant cells recruit regulatory $\mathrm{T}$ cells (Tregs) which produce immunosuppressive cytokines, transforming growth factor- $\beta$ (TGF- $\beta$ ) and interleukin-10 (IL-10) to suppress cytotoxic T cell response and maintain immune tolerance (61-63). Moreover, some subpopulations of myeloid-derived suppressor cells (MDSCs) can suppress natural killer (NK) cell cytotoxicity by blocking NK cellmediated production of interferons (IFNs) (63). In turn, the loss of IFNs induces the infiltration of MDSCs and Tregs $(64,65)$, and the presence of these immunosuppressive cells limits the efficacy of cytotoxic CD8+ T lymphocytes and gives immunosuppressive features to the tumor microenvironment. In addition, Programmed Death Ligand-1 (PD-L1) which is constitutively expressed on the surface of cancer cells can bind to PD-1 inducing the suppression of immune response, suggesting the cancer cell's attempt to escape cytotoxic immune cells (66). During CRC, different proinflammatory signals can enhance carcinogenesis by promoting angiogenesis and suppressing immune-mediated tumor elimination. In particular, it has been demonstrated that the activation of the transcription factor Nuclear Factor $-\kappa B(N F-\kappa B)$ in the tumor site results in production of pro-inflammatory cytokines like IL-6 and IL-1, which support proliferation and survival of cancer cells (67). NF- $\kappa \mathrm{B}$ also regulates the expression of tumor necrosis factor (TNF) and cyclooxygenase 2 (COX-2), which are overexpressed in an inflammatory CRC microenvironment and are involved in tumor growth promotion $(68,69)$. In addition to IL-6 and IL-1, other cytokines such as TGF, vascular endothelial growth factor (VEGF), C-X-C motif chemokine 3 (CXCL3), C-X-C motif chemokine 4 (CXCL4), and high mobility group box-1 (HMGB1) can be reprogrammed by tumor cells, giving rise to an immunosuppressive cytokine-dominated CRC microenvironment, which is a common mechanism for immunosurveillance escape of cancer (63). At present, it is not known if the lower prevalence of OD values for IgG against JCPyV VP1 antigens detected in CRC patients compared to HS, relies on a general or a specific impairment of CRC immune system. It is possible that JCPyV may infect colorectal cells, without being hampered by the altered immune system and transform them in tumor cells, acting as an oncogenic virus. Albeit our data suggest an inverse association between CRC and JCPyV, it is not yet clarified whether this polyomavirus is involved in the development of human CRC.

We may reason that $\mathrm{JCPyV}$ acts in genetically predisposed subjects when dysfunctions of the host immune system arise, because of disease-related factors, or when the immune system is not anymore fully active due to age. It is plausible that in some elderly subjects, the decline of immune system functions may favour the CRC onset and progression.

\section{DATA AVAILABILITY STATEMENT}

The raw data supporting the conclusions of this article will be made available by the authors, without undue reservation.

\section{ETHICS STATEMENT}

The studies involving human participants were reviewed and approved by County Ethics Committee of Ferrara. The patients/ participants provided their written informed consent to participate in this study.

\section{AUTHOR CONTRIBUTIONS}

Conceptualization: ET, IB, SP, FM and MT. Investigation and methodology: ET, IB, SP, EM. Clinical records and sample 
collection: GG, CF. Formal analysis and data curation: ET, IB, SP, EM, MT. Writing-original preparation: ET, MT. Supervision: MT, FM. All authors contributed to the article and approved the submitted version.

\section{FUNDING}

This research was funded by Associazione Italiana per la Ricerca sul Cancro (AIRC), Milan, grant number IG 21617 (to MT);

\section{REFERENCES}

1. Siegel RL, Miller KD, Fedewa SA, Ahnen DJ, Meester RGS, Barzi A, et al. Colorectal Cancer Statistics, 2017. CA Cancer J Clin (2017) 67:177-93. doi: 10.3322/caac.21395

2. Yang T, Li X, Montazeri Z, Little J, Farrington SM, Ioannidis JPA, et al. GeneEnvironment Interactions and Colorectal Cancer Risk: An Umbrella Review of Systematic Reviews and Meta-Analyses of Observational Studies. Int J Cancer (2019) 145:2315-29. doi: 10.1002/ijc.32057

3. Bray F, Ferlay J, Soerjomataram I, Siegel RL, Torre LA, Jemal A. Global Cancer Statistics 2018: GLOBOCAN Estimates of Incidence and Mortality Worldwide for 36 Cancers in 185 Countries. CA Cancer J Clin (2018) 68:394424. doi: 10.3322/caac.21492

4. Kuipers EJ, Grady WM, Lieberman D, Seufferlein T, Sung JJ, Boelens PG, et al. Colorectal Cancer. Nat Rev Dis Prim (2015) 1:15065. doi: 10.1038/nrdp.2015.65

5. Elsland D, Neefjes J. Bacterial Infections and Cancer. EMBO Rep (2018) 19 (11):e46632. doi: 10.15252/embr.201846632

6. Keum NN, Giovannucci E. Global Burden of Colorectal Cancer: Emerging Trends, Risk Factors and Prevention Strategies. Nat Rev Gastroenterol Hepatol (2019) 16:713-32. doi: 10.1038/s41575-019-0189-8

7. Chen H, Chen XZ, Waterboer T, Castro FA, Brenner H. Viral Infections and Colorectal Cancer: A Systematic Review of Epidemiological Studies. Int J Cancer (2015) 137:12-24. doi: 10.1002/ijc.29180

8. Del Valle L, Piña-Oviedo S. Human Polyomavirus Jcpyv and Its Role in Progressive Multifocal Leukoencephalopathy and Oncogenesis. Front Oncol (2019) 9:711. doi: 10.3389/fonc.2019.00711

9. Rotondo JC, Candian T, Selvatici R, Mazzoni E, Bonaccorsi G, Greco P, et al. Tracing Males From Different Continents by Genotyping JC Polyomavirus in DNA From Semen Samples. J Cell Physiol (2017) 232:982-5. doi: 10.1002/ jcp. 25686

10. Toumi W, Ripalti A, Ricciardiello L, Cherif A, Gargouri D, Bouhafa A, et al. Detection of a New JCV Strain of Genotype a in a Subpopulation of Colorectal Adenocarcinomas in Tunisia - Pubmed. New Microbiol (2017) 40:99-106.

11. Newcomb PA, Bush AC, Stoner GL, Lamper JW, John D Potter JB. No Evidence of an Association of JC Virus and Colon Neoplasia - Pubmed. Cancer Epidemiol Biomarkers Prev (2004) 13:662-6.

12. Assetta B, Atwood WJ. The Biology of JC Polyomavirus. Biol Chem (2017) 398:839-55. doi: 10.1515/hsz-2016-0345

13. Bononi I, Mazzoni E, Pietrobon S, Manfrini M, Torreggiani E, Rossini M, et al. Serum Igg Antibodies From Healthy Subjects Up to 100 Years Old React to JC Polyomavirus. J Cell Physiol (2018) 233:5513-22. doi: 10.1002/jcp.26457

14. Egli A, Infanti L, Dumoulin A, Buser A, Samaridis J, Stebler C, et al. Prevalence of Polyomavirus BK and JC Infection and Replication in 400 Healthy Blood Donors. J Infect Dis (2009) 199:837-46. doi: 10.1086/597126

15. Pinto M, Dobson S. BK and JC Virus: A Review. J Infect (2014) 68(Suppl 1): S2-8. doi: 10.1016/j.jinf.2013.09.009

16. White MK, Safak M, Khalili K. Regulation of Gene Expression in Primate Polyomaviruses. J Virol (2009) 83:10846-56. doi: 10.1128/jvi.00542-09

17. Coelho TR, Almeida L, Lazo PA. JC Virus in the Pathogenesis of Colorectal Cancer, an Etiological Agent or Another Component in a Multistep Process? Virol J (2010) 7:42. doi: 10.1186/1743-422X-7-42

18. Prado JCM, Monezi TA, Amorim AT, Lino V, Paladino A, Boccardo E. Human Polyomaviruses and Cancer: An Overview. Clinics (2018) 73(Suppl 1): e558s. doi: 10.6061/clinics/2018/e558s
University of Ferrara, Fondo di Ateneo per la Ricerca (FAR), grants 2019-2020 to MT, FM; Fondo di Incentivazione per la Ricerca (FIR), grant 2017 to FM, and grant 2020 to EM.

\section{ACKNOWLEDGMENTS}

We thank the Fondazione Umberto Veronesi (FUV), Milan, Italy for the fellowships given to Dr. Elena Torreggiani and Dr. Elisa Mazzoni.

19. Delbue S, Comar M, Ferrante P. Review on the Role of the Human Polyomavirus JC in the Development of Tumors. Infect Agent Cancer (2017) 12:10. doi: 10.1186/s13027-017-0122-0

20. Ricciardiello L, Baglioni M, Giovannini C, Pariali M, Cenacchi G, Ripalti A, et al. Induction of Chromosomal Instability in Colonic Cells by the Human Polyomavirus JC Virus. Cancer Res (2003) 63:7256-62.

21. Ksiaa F, Allous A, Ziadi S, Moncef Mokni MT. Assessment and Biological Significance of JC Polyomavirus in Colorectal Cancer in Tunisia - Pubmed. J BUON (2015) 20:762-9.

22. Coelho TR, Gaspar R, Figueiredo P, Mendonça C, Lazo PA, Almeida L. Human JC Polyomavirus in Normal Colorectal Mucosa, Hyperplastic Polyps, Sporadic Adenomas, and Adenocarcinomas in Portugal. J Med Virol (2013) 85:2119-27. doi: 10.1002/jmv.23705

23. Uleri E, Piu C, Caocci M, Ibba G, Sanges F, Pira G, et al. Multiple Signatures of the JC Polyomavirus in Paired Normal and Altered Colorectal Mucosa Indicate a Link With Human Colorectal Cancer, But Not With Cancer Progression. Int J Mol Sci (2019) 20(23):5965. doi: 10.3390/ijms20235965

24. Esmailzadeh N, Ranaee M, Alizadeh A, Khademian A, Saber Amoli S, Sadeghi F. Presence of JC Polyomavirus in Nonneoplastic Inflamed Colon Mucosa and Primary and Metastatic Colorectal Cancer. Gastrointest Tumors (2020) 7:30-40. doi: 10.1159/000504293

25. Yazdani Cherati A, Yahyapour Y, Ranaee M, Rajabnia M, Shokri Shirvani J, Hajiahmadi M, et al. No Evidence for an Association Between JC Polyomavirus Infection and Gastroduodenal Diseases. Gastrointest Tumors (2018) 5:47-53. doi: 10.1159/000489928

26. Sarvari J, Mahmoudvand S, Pirbonyeh N, Safaei A, Hosseini SY. The Very Low Frequency of Epstein-Barr JC and BK Viruses DNA in Colorectal Cancer Tissues in Shiraz, Southwest Iran. Polish J Microbiol (2018) 67:73-9. doi: 10.5604/01.3001.0011.6146

27. Sinagra E, Raimondo D, Gallo E, Stella M, Cottone M, Orlando A, et al. Could JC Virus Provoke Metastasis in Colon Cancer? World J Gastroenterol (2014) 20:15745-9. doi: 10.3748/wjg.v20.i42.15745

28. Rollison DE, Helzlsouer KJ, Lee JH, Fulp W, Clipp S, Hoffman-Bolton JA, et al. Prospective Study of JC Virus Seroreactivity and the Development of Colorectal Cancers and Adenomas. Cancer Epidemiol Biomarkers Prev (2009) 18:1515-23. doi: 10.1158/1055-9965.EPI-08-1119

29. Lundstig A, Stattin P, Persson K, Sasnauskas K, Viscidi RP, Gislefoss RE, et al. No Excess Risk for Colorectal Cancer Among Subjects Seropositive for the JC Polyomavirus. Int J Cancer (2007) 121:1098-102. doi: 10.1002/ijc.22770

30. Niv Y, Vilkin A, Levi Z. Patients With Sporadic Colorectal Cancer or Advanced Adenomatous Polyp Have Elevated Anti-JC Virus Antibody Titer in Comparison With Healthy Controls: A Cross-Sectional Study. J Clin Gastroenterol (2010) 44:489-94. doi: 10.1097/MCG.0b013e3181d7a347

31. Hampras SS, Viscidi RP, Helzlsouer KJ, Lee JH, Fulp WJ, Giuliano AR, et al. Prospective Study of Seroreactivity to JC Virus T-Antigen and Risk of Colorectal Cancers and Adenomas. Cancer Epidemiol Biomarkers Prev (2014) 23:2591-6. doi: 10.1158/1055-9965.EPI-14-0370

32. Moens U, Van Ghelue M, Song X, Ehlers B. Serological Cross-Reactivity Between Human Polyomaviruses. Rev Med Virol (2013) 23:250-64. doi: $10.1002 / \mathrm{rmv} .1747$

33. Barbanti-Brodano G, Sabbioni S, Martini F, Negrini M, Corallini A, Tognon M. BK Virus, JC Virus and Simian Virus 40 Infection in Humans, and Association With Human Tumors. Adv Exp Med Biol (2006) 577:319-41. doi: 10.1007/0-387-32957-9_23 
34. Viscidi RP, Rollison DEM, Viscidi E, Clayman B, Rubalcaba E, Daniel R, et al. Serological Cross-Reactivities Between Antibodies to Simian Virus 40, BK Virus, and JC Virus Assessed by Virus-Like-Particle-Based Enzyme Immunoassays. Clin Diagn Lab Immunol (2003) 10:278-85. doi: 10.1128/CDLI.10.2.278-285.2003

35. Pietrobon S, Bononi I, Mazzoni E, Lotito F, Manfrini M, Puozzo A, et al. Specific Igg Antibodies React to Mimotopes of BK Polyomavirus, a Small DNA Tumor Virus, in Healthy Adult Sera. Front Immunol (2017) 8:236. doi: 10.3389/fimmu.2017.00236

36. Mazzoni E, Bononi I, Pietrobon S, Torreggiani E, Rossini M, Pugliatti M, et al. Specific Antibodies Reacting to JC Polyomavirus Capsid Protein Mimotopes in Sera From Multiple Sclerosis and Other Neurological Diseases-Affected Patients. J Cell Physiol (2020) 235:5847-55. doi: 10.1002/jcp.29533

37. Pietrobon S, Bononi I, Lotito F, Perri P, Violanti S, Mazzoni E, et al. Specific Detection of Serum Antibodies Against Bkpyv, a Small DNA Tumour Virus, in Patients Affected by Choroidal Nevi. Front Microbiol (2017) 8:2059. doi: 10.3389/fmicb.2017.02059

38. Guerrini R, Salvadori S, Rizzi A, Regoli D, Calo G. Neurobiology, Pharmacology, and Medicinal Chemistry of Neuropeptide $S$ and Its Receptor. Med Res Rev (2010) 30:751-77. doi: 10.1002/med.20180

39. Tognon M, Corallini A, Manfrini M, Taronna A, Butel JS, Pietrobon S, et al. Specific Antibodies Reacting With SV40 Large T Antigen Mimotopes in Serum Samples of Healthy Subjects. PLoS One (2016) 11(1):e0145720. doi: 10.1371/journal.pone.0145720

40. Tagliapietra A, Rotondo JC, Bononi I, Mazzoni E, Magagnoli F, Maritati M, et al. Footprints of BK and JC Polyomaviruses in Specimens From Females Affected by Spontaneous Abortion. Hum Reprod (2019) 34:433-40. doi: 10.1093/humrep/dey375

41. Coursaget P, Samimi M, Nicol JTJ, Gardair C, Touzé A. Human Merkel Cell Polyomavirus: Virological Background and Clinical Implications. APMIS (2013) 121:755-69. doi: 10.1111/apm.12122

42. Touzé A, Gaitan J, Arnold F, Cazal R, Fleury MJ, Combelas N, et al. Generation of Merkel Cell Polyomavirus (MCV)-Like Particles and Their Application to Detection of MCV Antibodies. J Clin Microbiol (2010) 48:1767-70. doi: 10.1128/JCM.01691-09

43. Mazzoni E, Corallini A, Cristaudo A, Taronna A, Tassi G, Manfrini M, et al. High Prevalence of Serum Antibodies Reacting With Simian Virus 40 Capsid Protein Mimotopes in Patients Affected by Malignant Pleural Mesothelioma. Proc Natl Acad Sci USA (2012) 109:18066-71. doi: 10.1073/ pnas. 1213238109

44. Corallini A, Mazzoni E, Taronna A, Manfrini M, Carandina G, Guerra G, et al. Specific Antibodies Reacting With Simian Virus 40 Capsid Protein Mimotopes in Serum Samples From Healthy Blood Donors. Hum Immunol (2012) 73:502-10. doi: 10.1016/j.humimm.2012.02.009

45. van der Geest LGM, Lam-Boer J, Koopman M, Verhoef C, Elferink MAG, de Wilt JHW. Nationwide Trends in Incidence, Treatment and Survival of Colorectal Cancer Patients With Synchronous Metastases. Clin Exp Metastasis (2015) 32:457-65. doi: 10.1007/s10585-015-9719-0

46. Ogino S, Nowak JA, Hamada T, Phipps AI, Peters U, Milner DA, et al. Integrative Analysis of Exogenous, Endogenous, Tumour and Immune Factors for Precision Medicine. Gut (2018) 67:1168-80. doi: 10.1136/gutjnl2017-315537

47. Arastefar A, Ranjbar R, Behzad MA, Dezfulian K, Mehr HS, Aein A, et al. The Prevalence of CMV and EBV Among the Patients With the Colorectal Cancer; a Molecular Approach. J Immunother Cancer (2015) 3:P:379. doi: 10.1186/ 2051-1426-3-s2-p379

48. Syrjänen K. Geographic Origin is a Significant Determinant of Human Papillomavirus Prevalence in Oesophageal Squamous Cell Carcinoma: Systematic Review and Meta-Analysis. Scand J Infect Dis (2013) 45:1-18. doi: $10.3109 / 00365548.2012 .702281$

49. Mehrabani-Khasraghi S, Ameli M, Khalily F. Demonstration of Herpes Simplex Virus, Cytomegalovirus, and Epstein-Barr Virus in Colorectal Cancer. Iran BioMed J (2016) 20:302-6. doi: 10.22045/ibj.2016.08

50. Mou X, Chen L, Liu F, Lin J, Diao P, Wang H, et al. Prevalence of JC Virus in Chinese Patients With Colorectal Cancer. PLoS One (2012) 7(5):e35900. doi: 10.1371/journal.pone. 0035900

51. Kean JM, Rao S, Wang M, Garcea RL. Seroepidemiology of Human Polyomaviruses. PLoS Pathog (2009) 5(3):e1000363. doi: 10.1371/journal. ppat.1000363
52. Kjærheim K, Røe OD, Waterboer T, Sehr P, Rizk R, Hong YD, et al. Absence of SV40 Antibodies or DNA Fragments in Prediagnostic Mesothelioma Serum Samples. Int J Cancer (2007) 120:2459-65. doi: 10.1002/ijc.22592

53. Lundstig A, Eliasson L, Lehtinen M, Sasnauskas K, Koskela P, Dillner J. Prevalence and Stability of Human Serum Antibodies to Simian Virus 40 VP1 Virus-Like Particles. J Gen Virol (2005) 86:1703-8. doi: 10.1099/vir.0.80783-0

54. Ribeiro T, Fleury MJ, Granieri E, Castellazzi M, Martini F, Mazzoni E, et al. Investigation of the Prevalence of Antibodies Against Neurotropic Polyomaviruses BK, JC and SV40 in Sera From Patients Affected by Multiple Sclerosis. Neurol Sci (2010) 31:517-21. doi: 10.1007/s10072-010-0353-y

55. Engels EA, Rollison DE, Hartge P, Baris D, Cerhan JR, Severson RK, et al. Antibodies to JC and BK Viruses Among Persons With Non-Hodgkin Lymphoma. Int J Cancer (2005) 117:1013-9. doi: 10.1002/ijc.21277

56. Shi Y, Li Z, Zheng W, Liu X, Sun C, Laugsand JB, et al. Changes of Immunocytic Phenotypes and Functions From Human Colorectal Adenomatous Stage to Cancerous Stage: Update. Immunobiology (2015) 220:1186-96. doi: 10.1016/j.imbio.2015.06.003

57. McLean MH, Murray GI, Stewart KN, Norrie G, Mayer C, Hold GL, et al. The Inflammatory Microenvironment in Colorectal Neoplasia. PLoS One (2011) 6 (1):e15366. doi: 10.1371/journal.pone.0015366

58. Croci DO, Zacarías Fluck MF, Rico MJ, Matar P, Rabinovich GA, Scharovsky OG. Dynamic Cross-Talk Between Tumor and Immune Cells in Orchestrating the Immunosuppressive Network At the Tumor Microenvironment. Cancer Immunol Immunother (2007) 56:1687-700. doi: 10.1007/s00262-007-0343-y

59. Lasry A, Zinger A, Ben-Neriah Y. Inflammatory Networks Underlying Colorectal Cancer. Nat Immunol (2016) 17:230-40. doi: 10.1038/ni.3384

60. West NR, Mccuaig S, Franchini F, Powrie F. Emerging Cytokine Networks in Colorectal Cancer. Nat Rev Immunol (2015) 15:615-29. doi: 10.1038/nri3896

61. Jarnicki AG, Lysaght J, Todryk S, Mills KHG. Suppression of Antitumor Immunity by IL-10 and TGF- $\beta$-Producing T Cells Infiltrating the Growing Tumor: Influence of Tumor Environment on the Induction of CD4 + and CD8 + Regulatory T Cells. J Immunol (2006) 177:896-904. doi: 10.4049/jimmunol.177.2.896

62. OuYang L-Y, Wu X-J, Ye S-B, Zhang R-X, Li Z-L LW. Tumor-Induced Myeloid-Derived Suppressor Cells Promote Tumor Progression Through Oxidative Metabolism in Human Colorectal Cancer. J Transl Med (2015) 13:1-12. doi: 10.1186/s12967-015-0410-7

63. Zhang Y, Rajput A, Jin N, Wang J. Cancers Mechanisms of Immunosuppression in Colorectal Cancer. Cancers (Basel) (2020) 12(12):3850. doi: 10.3390/cancers12123850

64. Nishikawa H SS. Regulatory T Cells in Cancer Immunotherapy. Curr Opin Immunol (2014) 27:1-7. doi: 10.1016/j.coi.2013.12.005

65. Talmadge JE, Gabrilovich DI. History of Myeloid-Derived Suppressor Cells. Nat Rev Cancer (2013) 13:739-52. doi: 10.1038/nrc3581

66. Xiong Y, Ying Wang KT. Tumor Immune Microenvironment and NanoImmunotherapeutics in Colorectal Cancer. Nanomedicine (2019) 21:102034. doi: 10.1016/j.nano.2019.102034

67. Sakamoto K, Maeda S, Hikiba Y, Nakagawa H, Hayakawa Y, Shibata W, et al. Constitutive NF-KB Activation in Colorectal Carcinoma Plays a Key Role in Angiogenesis, Promotingtumor Growth. Clin Cancer Res (2009) 15(7):224858. doi: 10.1158/1078-0432.CCR-08-1383

68. Verzella D, Pescatore A, Capece D, Vecchiotti D, Ursini MV, Franzoso G, et al. Life, Death, and Autophagy in Cancer: NF-kb Turns Up Everywhere. Cancers Mechanisms of Immunosuppression in Colorectal Cancer. Cell Death Dis (2020) 11(3):210. doi: 10.1038/s41419-020-2399-y

69. Sheng J, Sun H, Yu F-B, Li B, Zhang Y, Zhu Y-T, et al. the Role of Cyclooxygenase-2 in Colorectal Cancer. Int J Med Sci (2020) 2020:1095101. doi: 10.7150/ijms.44439

Conflict of Interest: The authors declare that the research was conducted in the absence of any commercial or financial relationships that could be construed as a potential conflict of interest.

Copyright (c) 2021 Torreggiani, Bononi, Pietrobon, Mazzoni, Guerra, Feo, Martini and Tognon. This is an open-access article distributed under the terms of the Creative Commons Attribution License (CC BY). The use, distribution or reproduction in other forums is permitted, provided the original author(s) and the copyright owner(s) are credited and that the original publication in this journal is cited, in accordance with accepted academic practice. No use, distribution or reproduction is permitted which does not comply with these terms. 